Article

\title{
Comparing Teaching Methods of Mathematics at University Level
}

\author{
Michael Voskoglou
}

School of Technological Applications, Graduate Technological Educational Institute of Western Greece, 26334 Patras, Greece; voskogtlou@teiwest.gr

Received: 14 June 2019; Accepted: 28 July 2019; Published: 1 August 2019

\begin{abstract}
According to the views of social constructivism, learning takes place when individuals engage socially to talk about and act on shared problems or interests. In recent years, this approach has been very popular for the teaching and learning of mathematics in primary and secondary education. On the contrary, in tertiary education, it seems that most teachers still prefer the traditional way of delivering explicit mathematics instruction, sometimes combined with challenging questions and mathematical discourse with the students to promote conceptual understanding and critical analysis of the mathematical context. The paper at hand presents a classroom experiment comparing those two teaching methods at university level. The outcomes of the experiment were assessed and compared with the help of the Grade Point Average index to evaluate the student quality performance and by using grey numbers to evaluate their mean performance. Further empirical research is needed to obtain definitive results on the effectiveness of those two methods for teaching mathematics at university level.
\end{abstract}

Keywords: teaching and learning mathematics; social constructivism; explicit mathematics instruction; GPA index; grey numbers

\section{Introduction}

The constructivist views about learning and the socio-cultural approach have recently become very popular in school education (primary and secondary) for teaching and learning mathematics.

The idea that knowledge is a human construction supported by experience, first stated by Vico in the 18th century and further extended by Kant, greatly affected the epistemology of Piaget, who is considered to be the forerunner of the theory of constructivism for the process of learning. This theory appeared formally by von Glasersfeld who developed his ideas in the Piaget foundation of the United States in 1975 [1]. According to the constructivist view, knowledge is not passively received from the environment but actively constructed by synthesizing past knowledge and experience with new information. The "coming to know" is a process of adaptation based on and constantly modified by the individual's experience of the world.

On the other hand, the socio-cultural approach is based on Vygotsky's theory, claiming that knowledge is a product of culture and social interaction. Learning takes place when individuals engage socially to talk about and act on shared problems or interests. The Communities of Practice are groups of people (experts or practitioners in a particular field) who share a concern for something they do and learn how to do it better as they interact regularly, therefore having the opportunity to develop themselves personally and professionally $[2,3]$. The combination of the ideas of constructivism with the socio-cultural theories is known as social constructivism [4].

Mathematics teaching is intended to promote the learning of mathematics. However, while theory provides us with lenses for analyzing learning, the position of mathematics teaching remains theoretically anomalous and underdeveloped. We might see that one of the problems lies in the 
relationships between learning, teaching and the practice of teaching. Theories help us to analyze, or explain, but they do not provide recipes for action; rarely do they provide direct guidance for practice. According to Jaworski [3], one way to draw on theories of learning to explain or characterize teaching is to see teaching as a social practice, in which teachers are practitioners. For example, like the novice tailor being drawn into the practice of tailoring by perfecting processes and skills, by learning the rules of trade, etc., we might see the novice teacher being similarly drawn into the practice of teaching.

The principles of constructivism and of the socio-cultural theories for learning began to be applied for the teaching of school mathematics during the 1980s, when the failure of the introduction of the "new mathematics" had already become more than evident to everybody. However, in the mathematics departments of universities and in many other departments of the positive sciences, the majority of instructors still preferred the traditional way of delivering explicit mathematics instruction (EMI) to students. EMI is a systematic approach where students are guided through the learning process with clear statements about the purpose for learning the new skill, clear explanations and demonstrations of the instructional target, and supported practice with feedback until independent mastery has been achieved. It contains elements particularly well suited for supporting crucial working memory processing needed for learning [5]. However, it has been argued that EMI sometimes only increases the students' procedural knowledge and not their deep knowledge on the subject [6]. Thus, it may not promote conceptual understanding and critical analysis. Many teachers using EMI also proceed in the classroom to a series of challenging questions resulting in active mathematical discourse with students as a means to investigate mathematical thinking [7]. It is of worth noting that this is a practice compatible with the principles of social constructivism. For reasons of brevity, the combination of EMI with the challenging questions will be referred to in the rest of the paper as the "explicit" method, whereas the approach based purely on the principles of the social constructivism will be referred as the "constructive" method for teaching mathematics.

During the recent decades, social constructivism has been largely connected with mathematics learning, and attempts to build a confrontation between the above two ways of teaching mathematics that have already appeared in the literature, although many of them are related to elementary rather than university mathematics (e.g., see [8-10]). In a recent article, Lahdenpera, Postareff, and Ramo reviewed the corresponding research that has already been reported at the undergraduate university mathematics level, and they noted that, in certain cases, the findings are rather intertwined [11]. In the same work [11], the authors performed a quantitative study on the same group of students undertaking two different mathematics courses of the first semester of studies at the University of Helsinki. The results of the study have shown that the more student-centered (and, therefore, closer to the principles of social constructivism) course design succeeded in supporting more favorable approaches to learning, higher self-efficacy levels, and more positive student experiences of the teaching-learning environment.

The paper at hand attempts a comparison of the "explicit" and the "constructive" teaching method of mathematics at university level. For this, a classroom experiment was performed at the Graduate Technological Educational Institute (T. E. I.) of Western Greece. The outcomes of the experiment, expressed in linguistic terms (grades), were assessed and compared with the help of the Grade Point Average (GPA) index to evaluate the student quality performance and by using Grey Numbers (GNs) to evaluate their mean performance.

The rest of the paper is organized as follows: In Section 2, the classroom experiment is described in detail. Section 3 is devoted to the evaluation of the outcomes of the experiment, and Section 4 discusses the results obtained from this evaluation. 


\section{Classroom Experiment}

The subjects of the classroom experiment were the students of the first term of studies of two engineering departments of the School of Technological Applications of the Graduate T. E. I. of Western Greece. The curriculum of both departments includes a common introductory course of mathematics involving Differential and Integral Calculus in one variable, and elements from Analytic Geometry and Linear Algebra. The course was taught for both departments by the same instructor and the students used the same educational material (books, lecture notes, etc.).

The experiment, which was conducted ethically (no special permission was needed according to Greek educational laws), took place before and after teaching the Conic Sections. Note that the students of the two departments had the same mathematical background from their school education and, according to the grades obtained in the general examination of mathematics for their entry into tertiary education, they had almost the same (on average) mathematical skills. To be sure about this, a written pre-test was performed before the teaching of the Conic Sections involving some simple theoretical questions and numerical exercises on the subject. The outcomes of the test showed that, in fact, the knowledge and potential of the two departments on the subject were of the same level (see Table A1 in Appendix A). There were also no other differences among the students with respect to age, gender, major, etc.

The "explicit" teaching method was applied for the first department $\left(D_{1}\right)$, which played the role of the control group. The instructor developed the subject on the board step-by-step, remembering to maintain a dialogue with the students by addressing suitable questions. The theoretical instruction was followed by a series of exercises, applications, and problems, where the students took an active part. The purpose of this treatment was to embed the acquired theoretical knowledge, generalize it to a variety of situations and, finally, categorize it in the student cognitive schemas so that it could be retrieved from their memory whenever needed, and properly used for tackling related problems.

On the contrary, the "constructive" teaching method was applied for the students of the second department $\left(\mathrm{D}_{2}\right)$, which will be referred here as the experimental group. In applying this method, the instructor addressed the new knowledge in the form of a problem to be solved with the help of already existing knowledge. The students were divided in small collaborating groups and they were left to work alone on their papers for the solution of the problem. The instructor was inspecting their efforts and guiding their inquiries with proper hints or instructions. In the next stage, the student groups announced their solutions or efforts to solve the problem. A guided-by-the-instructor discussion followed, analyzing the reasons of possible failures and comparing the solutions obtained. The last stage involved drawing the final conclusions and the rigorous formation of new knowledge and concepts. A similar process was followed for the solution of the corresponding exercises and problems.

Note that a great part of the teaching process for the experimental group took place not in the classroom but in the computer laboratory. There, the students had the opportunity to use proper mathematical software, or other suitable procedures (codes) that had been previously designed by experts, to find the solutions of the corresponding problems before attempting to solve them on their papers. This is based on findings by Dubinsky and his collaborators-in developing the APOS/ACE instructional treatment of mathematics-that one can usually design computer task such that, if a student engages in it, it is fairly likely to build the mental construction that leads to the learning of the corresponding mathematical topic [12].

After the end of the teaching process, a written post-test was performed for both departments involving, this time, more advanced theoretical questions and problems (see Appendix B). The individual student performance in the test was assessed with the help of the linguistic grades: $\mathrm{A}=$ excellent, $\mathrm{B}=$ very good, $\mathrm{C}=$ good, $\mathrm{D}=$ satisfactory, and $\mathrm{F}=$ failed. The very existence of the scores has a permanent effect on the nature and direction of student learning, causing to them a state of anxiety. On the contrary, the linguistic assessment, which is often used in practice, prevents dilemmas about the exact numerical score corresponding to the performance of each student by replacing it with an interval of scores. In this way, student anxiety is significantly reduced. 
The outcomes of the post-test and the methods used for their evaluation will be exposed in the next section.

\section{Results}

\subsection{Outcomes of the Experiment}

Table 1 depicts the performance of the two departments in the post-test:

Table 1. Outcomes of the post-test.

\begin{tabular}{ccc}
\hline Grade & $\mathbf{D}_{\mathbf{1}}$ & $\mathbf{D}_{\mathbf{2}}$ \\
\hline A & 3 & 19 \\
B & 10 & 9 \\
C & 20 & 19 \\
D & 34 & 15 \\
F & 8 & 10 \\
\hline Total & 75 & 72 \\
\hline
\end{tabular}

\subsection{Quality Performance (GPA Index)}

The Grade Point Average (GPA) index is a weighted average, frequently used for evaluating the overall quality performance of a group of homogeneous objects (individuals, machines, etc.) with respect to a certain common activity. The quality performance of the group is evaluated by assigning greater coefficients (weights) to the higher individual performances. Namely, let $\mathrm{n}$ be the total number of objects of the corresponding group and let $\mathrm{n}_{\mathrm{A}}, \mathrm{n}_{\mathrm{B}}, \mathrm{n}_{\mathrm{C}}, \mathrm{n}_{\mathrm{D}}$, and $\mathrm{n}_{\mathrm{F}}$ be the numbers of those objects whose performance was characterized as excellent, very good, good, satisfactory, and as a failure, respectively. Then, the GPA index is calculated by this formula [13] (Chapter 6, p. 125):

$$
\mathrm{GPA}=\frac{0 \mathrm{n}_{\mathrm{F}}+1 \mathrm{n}_{\mathrm{D}}+2 \mathrm{n}_{\mathrm{C}}+3 \mathrm{n}_{\mathrm{B}}+4 \mathrm{n}_{\mathrm{A}}}{\mathrm{n}} .
$$

Obviously, the GPA index takes values between 0 (worst performance, $\mathrm{n}_{\mathrm{F}}=\mathrm{n}$ ) and 4 (best performance, $n_{A}=n$ ). Replacing the data of Table 1 with those of Equation (1), one finds the values GPA $=1.55$ for $\mathrm{D}_{1}$ and GPA $=2.17$ for $\mathrm{D}_{2}$. Therefore, the experimental group demonstrated a better-quality performance than the control group. More specifically, the difference $2.17-1.55=0.62$ between the GPA values for the two groups corresponds to a $15.5 \%$ better performance for the experimental group.

\subsection{Mean Performance (By Using Grey Numbers (GNs))}

The use of linguistic grades for assessing individual student performance prevents the application of conventional statistical methods for analyzing the student performance and, in particular, the calculation of the mean value of all student scores for evaluating the student group mean performance. Instead, in earlier works, we have developed two equivalent methods for estimating the student mean performance by using triangular fuzzy numbers and grey numbers as tools, e.g., [14] (Sections 5.2 and 6.2). Here, we prefer the use of grey numbers, as they reduce the required computational burden with respect to the triangular fuzzy numbers.

\subsubsection{Grey Numbers (GNs)}

It is recalled that a GN is a number with unknown position within its known boundaries. Therefore, a GN can be represented with the help of a closed real interval in the form $A \in[a, b]$. When $a=b, A$ becomes an ordinary real number, called a white number. A GN may also be associated with a whitening function $g:[a, b] \rightarrow[0,1]$, such that the closer $g(x)$ is to 1 , the greater the probability of $x$ to be the 
white number representing the corresponding GN. However, for our purposes here, there is no need to introduce such functions. In this case, the real number whitening $\mathrm{A}$ is calculated by

$$
\mathrm{W}(\mathrm{A})=\frac{\mathrm{a}+\mathrm{b}}{2} .
$$

The well-known arithmetic of the closed real intervals [15] has been used to define the corresponding arithmetic operations on GNs. For our purposes here, we are only going to use the following two operations:

- If $A \in[a, b]$ and $B \in[c, d]$ are given GNs, their sum is defined to be the GN $A+B \in[a+c, b+d]$.

- If $\mathrm{k}$ is a positive real number, then the scalar product $\mathrm{kA}$ is defined to be the GN $\mathrm{kA} \in[\mathrm{ka}, \mathrm{kb}]$.

More details about the GNs can be found in [10] (Section 6.1) and a detailed exposition can be found in the book [16].

\subsubsection{Method}

A GN is attached to each linguistic grade, denoted for simplicity by the same letter, as follows:

$\mathrm{A} \in[85,100], \mathrm{B} \in[75,84], \mathrm{C} \in[60,74], \mathrm{D} \in[59,50]$, and $\mathrm{F} \in[49,0]$. Then, it appears logical to consider the $G N M=\frac{1}{n}\left(n_{A} A+n_{B} B+n_{C} C+n_{D} D+n_{F} F\right)$ as the grey representative of the student group mean performance. It is straightforward to check that $M \in\left\{\mathrm{m}_{1}, \mathrm{~m}_{2}\right]$, where

$$
\begin{aligned}
\mathrm{m}_{1} & =\frac{85 \mathrm{n}_{\mathrm{A}}+75 \mathrm{n}_{\mathrm{B}}+60 \mathrm{n}_{\mathrm{C}}+50 \mathrm{n}_{\mathrm{D}}+0 \mathrm{n}_{\mathrm{F}}}{\mathrm{n}}, \\
\mathrm{m}_{2}= & \frac{100 \mathrm{n}_{\mathrm{A}}+84 \mathrm{n}_{\mathrm{B}}+69 \mathrm{n}_{\mathrm{C}}+59 \mathrm{n}_{\mathrm{D}}+49 \mathrm{n}_{\mathrm{F}}}{\mathrm{n}} .
\end{aligned}
$$

Observe that $\mathrm{m}_{1}$ is equal to the mean value of the student scores when the minimal possible score corresponds to the qualitative grade characterizing the performance of each student (i.e., 85 for A, 75 for $B$, etc.). Similarly, $m_{2}$ is equal to the mean value of the corresponding maximal scores (i.e., 100 for A, 84 for $B$, etc.). This ensures that the value of $W(M)=\frac{m_{1}+m_{2}}{2}$, obtained by applying Equation (2), provides a reliable estimation of the student group mean performance.

Replacing the data of Table 1 with those of Equation (3), one finds the values $\mathrm{m}_{1}=54.23, \mathrm{~m}_{2}=69.29$ for $\mathrm{D}_{1}$, and $\mathrm{m}_{1}=58.06, \mathrm{~m}_{2}=75.51$ for $\mathrm{D}_{2}$. Therefore, $\mathrm{W}(\mathrm{M})=61.76$ for $\mathrm{D}_{1}$ and $\mathrm{W}(\mathrm{M})=66.78$ for $\mathrm{D}_{2}$, which shows again that the experimental group demonstrated a better mean performance than the control group.

However, in this case, the difference $66.78-61.76$ corresponds only to a $5.02 \%$ better performance for the experimental group.

\section{Discussion and Conclusions}

The results of the classroom experiment underline the superiority of the experimental group with respect to the control group. Taking also into account that the "constructive" teaching method was a new experience for the students of the experimental group, we have a strong indication that this method could further improve student performance. However, a number of important questions still remain open for further research:

- Would the experimental group performance be better or worse if the students performed the same activities alone (without social interaction)?

- How much has each one of the undertaken activities (computer tasks, classroom discussions, problem-solving, etc.) contributed, or not, to the improvement of the performance of the experimental group?

- How important does the measurement (apart from the performance) of other factors affect the process of learning, like motivation, self-efficacy, gender, etc.? 
Another point to be discussed here is the fact that the experimental group demonstrated a $15.5 \%$ better-quality performance, but only a $5.02 \%$ better mean performance with respect to the control group. This indicates that the teaching method based on the principles of social constructivism helped the good students more. However, what happened with the lower-level students? From Table 1, one observes that the failure percentage was greater for the experimental group $\left(\frac{10}{72}>\frac{8}{75}\right)$, which means that the above method created more problems for those students. Therefore, another point for future research is to study how one can improve the situation for those students, maybe by finding ways to combine the "explicit" with the "constructive" teaching method, or by grouping the students by ability and not by mixed ability, like we did in the present experiment.

One of the targets of the present work was to propose a way (use of grey numbers) of evaluating the grey data obtained by performing the student assessment in terms of linguistic grades (as it frequently happens in practice) and not by exact numerical scores. This approach has its own importance, but it prevents the application of conventional statistical methods and tests. Therefore, analogous future experiments are suggested with numerical scores in order to be able to test statistically the significance of their outcomes.

In general, as a single experiment is usually not enough to cover all the cases and to obtain definite conclusions, more experimental research is needed supporting the present one and the earlier research reported in our introduction.

Funding: This research received no external funding.

Conflicts of Interest: The author declares no conflict of interest

\section{Appendix A}

The Questions and Outcomes of the Pre-Test

1. Give the definitions of the ellipse, of the parabola, and of the hyperbola.

2. Write down the equations of the ellipse and of the hyperbola with the center at the origin and the axes the same as those of the corresponding coordinate system.

3. Find the equation of the circle with diameter $A B$, where $A(-1,3)$ and $B(3,5)$.

4. Find the equation of the parabola with the vertex at the origin and the axis OX having as a tangent the straight line $3 x-y+1=0$.

Table A1. Outcomes of the pre-test.

\begin{tabular}{ccc}
\hline Grade & $\mathbf{D}_{\mathbf{1}}$ & $\mathbf{D}_{\mathbf{2}}$ \\
\hline A & 12 & 11 \\
B & 11 & 11 \\
C & 29 & 28 \\
D & 13 & 13 \\
F & 10 & 9 \\
\hline Total & 75 & 72 \\
\hline
\end{tabular}

Working as in Section 3.2, one finds that the GPA index is equal to 2.03 for both departments, which therefore demonstrates the same quality performance. Also, working with grey numbers as in Section 3.3, one finds the values $\mathrm{m}_{1}=56.46, \mathrm{~m}_{2}=71.76$ for $\mathrm{D}_{1}$, and $\mathrm{m}_{1}=56.8, \mathrm{~m}_{2}=71.75$ for $\mathrm{D}_{2}$. Therefore, $\mathrm{W}(\mathrm{M})=64.11$ for $\mathrm{D}_{1}$ and $\mathrm{W}(\mathrm{M})=64.27$ for $\mathrm{D}_{2}$, which shows that the two departments demonstrate roughly the same mean performance. 


\section{Appendix B}

The Questions of the Post-Test

1. Write down the general equation of the second degree in two unknowns and the conditions under which it represents a real ellipse, parabola, or hyperbola.

2. Design a parabola and find its equation in a suitable coordinate system.

3. Find the equations of the tangents of the hyperbola $x^{2}-y^{2}=8$ that form an angle of $60^{\circ}$ with the axis XX.

4. Find the locus of the centers of the circles touching inside the circle $x^{2}+y^{2}-4 x-21=0$ and outside the circle $x^{2}+y^{2}=1$.

\section{References}

1. von Glasersfeld, E. Learning as a Constructive Activity. In Problems of Representation in the Teaching and Learning of Mathematics; Janvier, C., Ed.; Lawrence Erlbaum: Hillsdale, NJ, USA, 1987; pp. 3-17.

2. Wenger, E. Communities of Practice: Learning, Meaning and Identity; Cambridge University Press: Cambridge, UK, 1998.

3. Jaworski, B. Theory and practice in mathematics teaching development: Critical inquiry as a mode of learning in teaching. J. Math. Teach. Educ. 2006, 9, 187-211. [CrossRef]

4. Driver, R.; Asoko, H.; Leach, J.; Mortimer, E.; Scott, P. Constructing Scientific Knowledge in the Classroom. Educ. Res. 1994, 23, 5-12. [CrossRef]

5. Doabler, T.; Fien, H. Explicit Mathematics Instruction: What teachers can do for teaching students with mathematics difficulties. Interv. Sch. Clin. 2013, 48, 276-285. [CrossRef]

6. Smith, J.L.M.; Saez, L.; Doabler, C.T. Using explicit and systematic instruction to support working memory. Teach. Except. Child. 2016, 48, 275-281. [CrossRef]

7. Kinard, J.T. Rigorous Mathematical Thinking: Conceptual Formation in the Mathematics Classroom; Cambridge University Press: Cambridge, UK, 2008.

8. Ernest, P. Social Constructivism as a Philosophy of Mathematics; State University of New York Press: New York, NY, USA, 1998.

9. Sfard, A. On reform movement and the limitsof mathematical discourse. Math. Think. Learn. 2000, 2, 157-189. [CrossRef]

10. Lassani, A.; Yunus, A.S.M.; Abu Bakar, K.B.T. Comparison of New Mathematics Teaching Methods with Traditional Method. People Int. J. Soc. Sci. 2017, 3, 1285-1297. [CrossRef]

11. Lahdenpera, J.; Postareff, L.; Ramo, J. Supporting quality of learning i8n university mathematics: A comparison of two instructional designs. Int. J. Res. Undergrad. Mat. Educ. 2019, 5, 75-96. [CrossRef]

12. Arnon, I.; Cottrill, J.; Dubinsky, E.; Oktac, A.; Roa, S.; Trigueros, M.; Weller, K. APOS Theory: A Framework for Research and Curriculum Development in Mathematics Education; Springer: New York, NY, USA; Heidelberg, Germany; Dordrecht, The Netherland; London, UK, 2014.

13. Voskoglou, M.G.R. Finite Markov Chain and Fuzzy Logic Assessment Models: Emerging Research and Opportunities; Createspace.com-Amazon: Columbia, SC, USA, 2017.

14. Voskoglou, M.G.R. Methods for Assessing Human-Machine Performance under Fuzzy Conditions. Mathematics 2019, 7, 230. [CrossRef]

15. Moore, R.A.; Kearfort, R.B.; Clood, M.J. Introduction to Interval Analysis, 2nd ed.; SIAM: Philadelphia, PA, USA, 1995.

16. Liu, S.F.; Lin, Y. Advances in Grey System Research; Springer: Berlin/Heidelberg, Germany, 2010. 